\title{
A flow injection-fluorometric method for the determination of ammonium in fresh and saline waters with a view to in situ analyses
}

\author{
Alain Aminot*, Roger Kérouel and Dominique Birot \\ IFREMER-Brest, BP 70, 29280 Plouzané, France \\ *: Corresponding author : Tel.: +33-298-22-43-61; fax: +33-298-22-45-48; email: aaminot@ifremer.fr
}

\begin{abstract}
A version of the orthophthaldialdehyde-fluorescence ammonium determination for flow injection analysis (FIA) is presented here, with a view to its use for in situ, low-power consumption systems. Thus, the reaction temperature was limited to $30^{\circ} \mathrm{C}$ and FIA was used in stop-flow mode (3

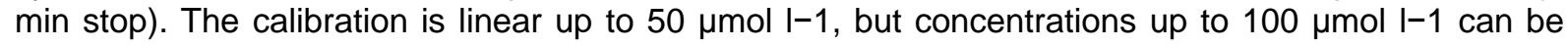
measured. Repeatability is around $1 \%$ in the range of $0.5-4 \mu \mathrm{mol} \mathrm{I-1}$ and the detection limit is about $0.03 \mu \mathrm{mol} \mathrm{I-1}$. Over the salinity range of $5-35$ (seawater practical salinity scale) the salt effect is almost negligible (within $\pm 2 \%$ ); and below salinity of 5 it increases to a maximum of $-9 \%$ in fresh water compared to seawater. Hydrogen carbonate, dissolved oxygen and turbidity (either suspended sediments or phytoplankton cells) have almost no adverse effect in a wide range of concentrations, covering most natural water conditions. Relative interference of primary amines is negligible and mercury (a common sample preservative) does not depress the signal up to $20 \mathrm{mg} \mathrm{l}-1 \mathrm{Hg}$ II. Sulfide, that may be present in areas with anoxic waters, depresses the signal only slightly and linearly ( $-9 \%$ at $100 \mu \mathrm{mol} \mathrm{I-1} \mathrm{S2-).} \mathrm{The} \mathrm{method} \mathrm{appears} \mathrm{to} \mathrm{be} \mathrm{convenient} \mathrm{for} \mathrm{the} \mathrm{determination} \mathrm{of} \mathrm{ammonium} \mathrm{in}$ most coastal, estuarine and fresh waters. Sample throughput is $9 \mathrm{~h}-1$. The performance of the method can be improved, either by increasing the reaction time (low throughput) or, if enough energy is available, by increasing the reaction temperature (non-stop-flow mode, high throughput). Combining FIA and fluorometry appears to be interesting for in situ determination (submersible devices) of dissolved compounds in environments with variable salinity and turbidity (especially coastal and estuarine waters).
\end{abstract}

Keywords: ammonium, determination, flow-injection analysis, fluorometry, in situ 


\section{INTRODUCTION}

Although ammonium is an important link in the nitrogen cycle of aquatic ecosystems, its determination is still a delicate task. Two main reasons for this can be put forward: (i) it is highly susceptible to contamination, and (ii) the classic indophenol-blue (IPB) method does not appear to be well controlled in many laboratories (Aminot et al., 1997). For use in unpolluted natural media, most methods suffer either from lack of sensitivity (selective electrodes), low throughput (gas chromatography) or a more or less significant salt effect (IPB, dialysis-continuous flow), and sometimes from a combination of several of these problems.

Fluorometric determination of ammonium in any natural waters by the orthophthaldialdehyde (OPA)-sulfite reagent has recently offered new possibilities of measuring this nutrient in aquatic systems, either automatically or manually (Kérouel and Aminot, 1997; Holmes et al., 1999). This method does not include dialysis and has some advantages, like simple, non-toxic reagents, high sensitivity and low salt effect. In order to enlarge this reaction's field of application, work is underway to transfer it to flow injection analysis (FIA) with specific criteria suitable for in situ systems.

The generally accepted technique for in situ determination is flow injection analysis. It is more robust than conventional air segmented flow analysis, almost insensitive to pressure and therefore more convenient for use in submersible analyzers. Johnson et al. (1986) had already proposed such a submersible device for silicate and sulfide, as well as for nitrite and nitrate (Johnson et al., 1989). New systems were recently proposed by Daniel et al. (1995a, 1995b) for nitrite and nitrate and by Vuillemin et al. (1999) for nitrate phosphate and silicate. Daniel et al. (1995b) paid particular attention to artifacts due to salinity variation in coastal waters. Indeed, using colorimetric detection, FIA is hindered by large artifacts and blank peaks generated when the refractive indexes of the carrier stream and injected solution differ. This occurs when seawater samples are analyzed and is worsened when the salinity changes from sample to sample. To overcome this problem, Thomsen et al. (1983) diluted both reagents with the sample before mixing while Daniel et al. (1995b) used a dual-wavelength measurement system.

In other respects, FIA is characterized by a high axial diffusion (hence by rather short manifolds) which makes it difficult to apply it to slow reactions. However, combining it with fluorometry, which is very sensitive, may balance out this disadvantage since the time required to produce a measurable signal can be very short. In addition, optical interference due to refractive index variation (Schlieren effect) has been found to be negligible in the fluorometric ammonium method (Kérouel and Aminot, 1997). This appears to be a significant improvement over colorimetric detection, for estuarine studies. Moreover, owing to the high

reproducibility of reaction conditions in continuous flow analysis, the signal can be measured at any moment of the reaction development without introducing significant errors, which is particularly interesting for slow reactions.

This paper deals with combining FIA and fluorometric detection as a high-performance tool to determine ammonium in aquatic ecosystems, with particular attention to its potential application to in situ measurements. The laboratory-automated method already developed (Kérouel and Aminot, 1997; called the SFA version) served as a basis for the present adaptation. The aim of this work was to determine optimum reaction conditions able to provide acceptable performance in coastal and estuarine waters, within the constraint of keeping power consumption as low as possible. 


\section{MATERIAL AND METHOD}

\subsection{Apparatus}

Figure 1 describes the apparatus. The manifold was made of $0.8 \mathrm{~mm}$ internal diameter PTFE tubing (up to the flowcell) connected using Upchurch flangeless connectors. For the experiments described here, the reaction coil was simply immersed in a water bath maintained at the required temperature using a cryothermostat. Several detectors were successfully tested (including the filter fluorometer Fluoro-Tec A4-2001A from St. John Associated, Inc., USA and the spectrofluorometer FP-1520 from Jasco Corporation, Japan), but filter detectors showed a small sensitivity drift which required more frequent standard control.

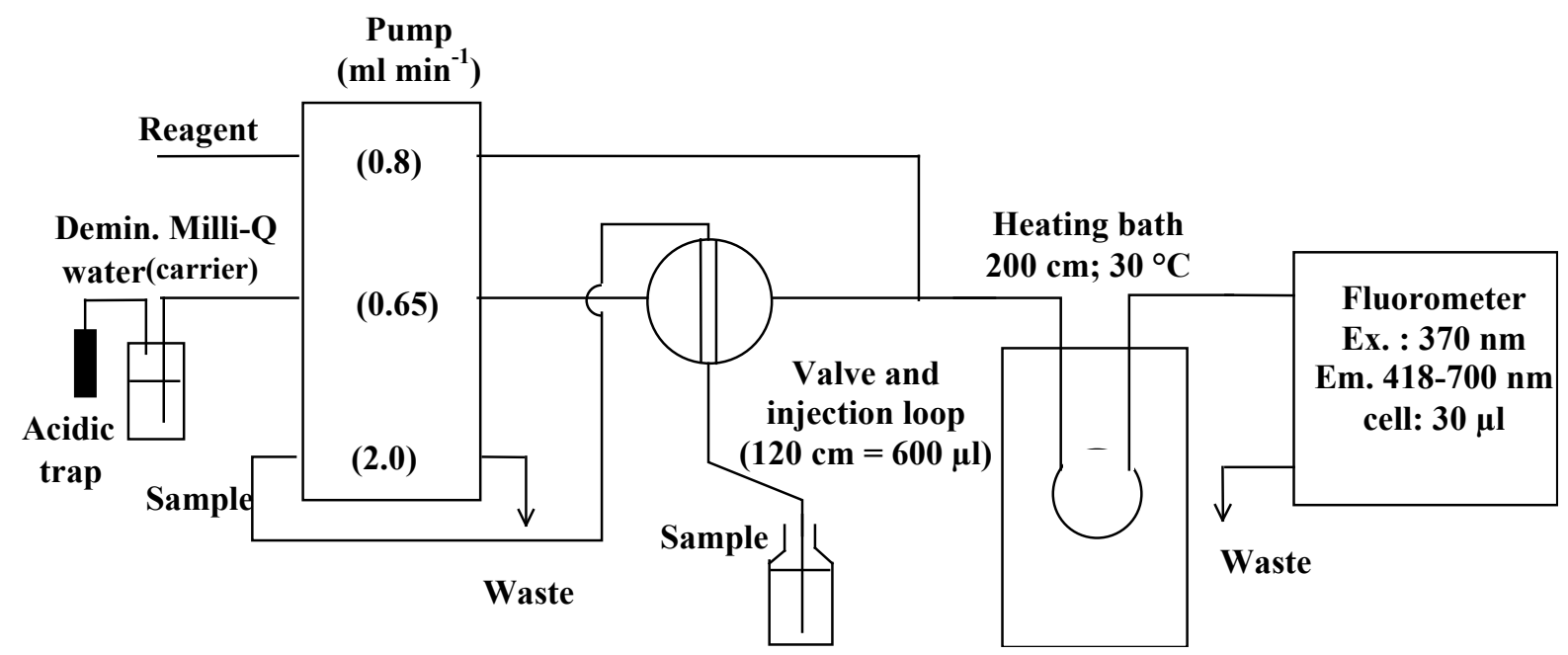

Figure 1. FIA manifold for the determination of ammonia in natural waters. Stop-flow mode: 3 min stop. Material used: pump Gilson Minipuls (setting: 6 rpm); valve Selec-CIL 99T; detector Fluoromonitor III (Laboratory Data Control, USA) with a $360 \mathrm{~nm}$ Black Fluorescence lamp.

\subsection{Reagents}

Except for the OPA solution, stock solutions were prepared with freshly drawn, ultrapure deionized Milli-Q water. Unless mentioned otherwise, Merck reagent-grade chemicals were used. The reagents include the following :

- Borate $\left(\mathrm{Na}_{2} \mathrm{~B}_{4} \mathrm{O}_{7}, 10 \mathrm{H}_{2} \mathrm{O}\right)$ stock solution: $20 \mathrm{~g} \mathrm{l}^{-1}$.

- OPA stock solution: $40 \mathrm{~g} \mathrm{l}^{-1}$ standard grade o-phtaldialdehyde (P-1378 Sigma Chemical Co) in high purity ethanol (Carlo Erba 414607); avoid using aged OPA crystals: they may not totally dissolve, produce larger baseline artifacts and reduce the linear range.

- Sodium sulfite stock solution: $60 \mathrm{~g} \mathrm{l}^{-1}$.

- Carrier: Milli-Q water spiked with $0.5 \%$ (v/v) ammonia-free seawater or $0.2 \mathrm{~g} \mathrm{l}^{-1}$ $\mathrm{NaCl}$; the carrier is protected from atmospheric ammonia by an acidic trap (Kérouel and Aminot, 1997).

The working reagent is prepared by mixing $30 \mathrm{ml}$ of OPA stock solution with 11 of borate stock solution, then adding $3 \mathrm{ml}$ of sulfite stock solution and $0.2 \mathrm{ml}$ of $30 \%$ Brij solution (wetting agent). The working solution is protected from light and left to stand for 
several hours before use. The reaction medium contained borate $28 \mathrm{mmol}^{-1}$, OPA 4.7 $\mathrm{mmol}^{-1}$ and sulfite $0.76 \mathrm{mmol} \mathrm{l}^{-1}$.

In all experiments the so-called "fresh water" was made by adding $0.5 \%$ ammoniumfree, aged seawater (salinity of 35) to Milli-Q water. The ionic strength generated by the $\sim 200 \mathrm{mg} \mathrm{l}^{-1}$ total dissolved solids thus added prevented ammonium adsorption, a major problem which occurs in demineralized water (seawater can be replaced with $0.2 \mathrm{~g} \mathrm{l}^{-1} \mathrm{NaCl}$ ).

Primary ammonium standards were prepared using $\left(\mathrm{NH}_{4}\right)_{2} \mathrm{SO}_{4}$ (Baker, 0032) dried at $105^{\circ} \mathrm{C}$ for $2 \mathrm{~h}$ and kept in a dessicator: $66.67 \mathrm{mg} \mathrm{l}^{-1}$ is equivalent to $1 \mathrm{mmol}^{-1} \mathrm{NH}_{4}$.

For interference testing, the following compounds were used: sodium hydrogen carbonate, sodium sulfide, mercuric chloride, methylamine hydrochloride, ethylamine hydrochloride, glycine, serine, alanine, valine, threonine, tryptophan, aspartic acid, urea.

\section{RESULTS}

\subsection{Manifold optimization}

At ambient temperature, it takes several hours to complete the reaction (see Holmes et $a l ., 1999$ ) and its rate is also strongly temperature-dependent. Experiments (Fig. 2a and 2b) showed how signal intensity is related to the stop-flow time, length of the injection loop and temperature. These results suggest that the reaction has an initializing phase before reaching a significant rate. In such a case, too low temperature and/or too short reaction times produce only very small signals. However, the low power consumption constraint imposed (i) a heated reaction coil of $1 \mathrm{ml}$ at most $(2 \mathrm{~m})$ and (ii) the lowest possible reaction temperature. Heating slightly above usual ambient temperature was important for good regulation and, therefore, the temperature was set at $30{ }^{\circ} \mathrm{C}$. As shown in Fig. $2 \mathrm{~b}$, reaction sensitivity to temperature is about $20 \%$ per degree Celsius at $30^{\circ} \mathrm{C}$, which requires good thermostatization for satisfactory reproducibility. This selected temperature is well below the temperature range $\left(75\right.$ to $\left.95^{\circ} \mathrm{C}\right)$ of the other automated methods (Genfa and Dasgupta, 1989; Kérouel and Aminot, 1997), consequently, adequate sensitivity required a reaction time of several minutes. Because of the limited length of the reaction coil, the stop-flow technique was applied: the flow was stopped for $3 \mathrm{~min}$ after the sample and the reagent were mixed. Again, this time is a compromise between signal intensity, power consumption and sample throughput. An injection loop of $1.2 \mathrm{~m}(600 \mu \mathrm{l})$ was found to be satisfactory.

\subsection{Reagent concentration}

To avoid risk of precipitation of sodium tetraborate in the reagent for an eventual submersible application, its concentration was decreased from $30 \mathrm{~g} \mathrm{l}^{-1}$ in the SFA version to $20 \mathrm{~g}^{-1}$. However, to keep the borate concentration in the reaction medium as high as possible the ratio reagent/sample is now $1 / 0.8$ compared to $0.8 / 1$ in the SFA version. Since the reaction conditions have been drastically changed from the basic method (mixing process, temperature, reaction time), the concentrations of the active reagents were re-examined. FIA reaction time and temperature obviously lead to a much lower signal than in SFA, but this could be amplified by increasing the reagent concentrations with respect to the SFA version. When the OPA concentration was increased by $50 \%$, a $25 \%$ gain on peak height was obtained (because of the high cost of OPA, a larger increase was not considered to be realistic). Figure $2 \mathrm{c}$ shows 

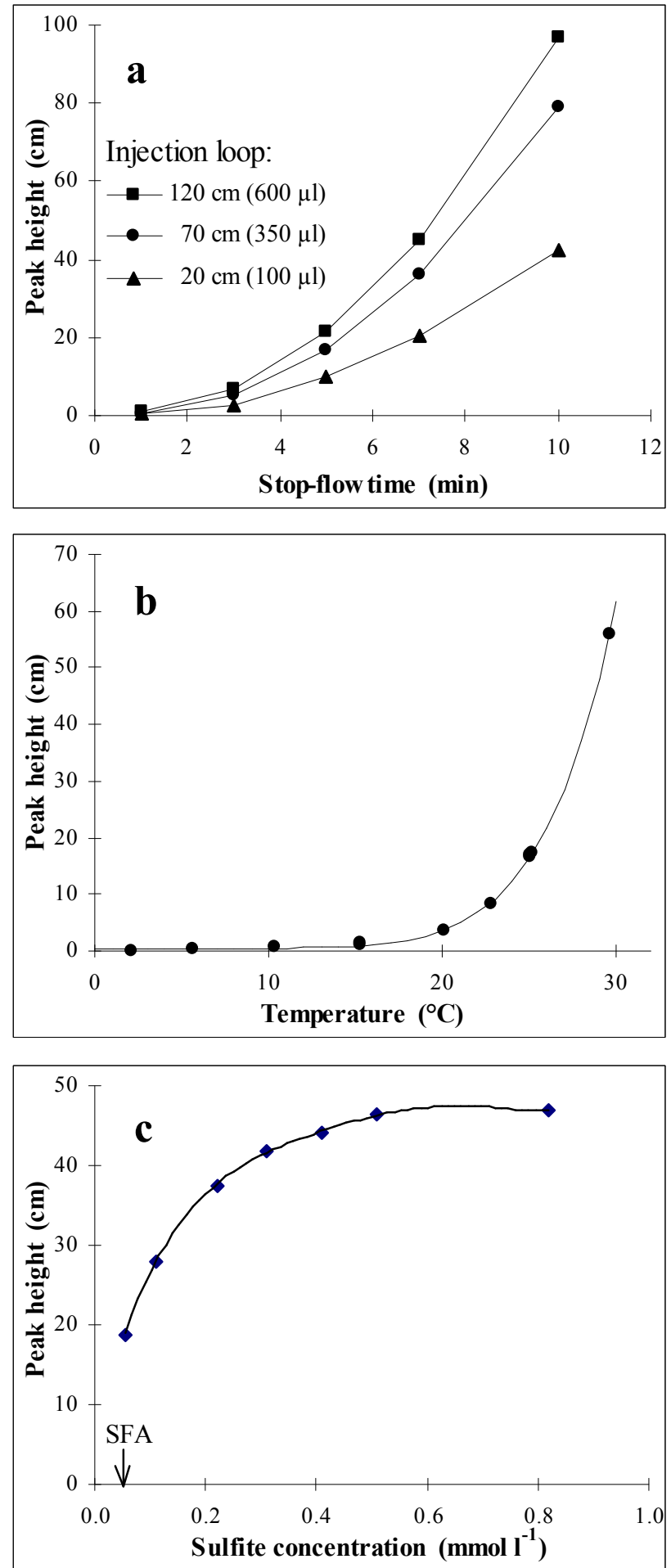

Figure 2. Variation of the peak height as a function of: a) stop-flow time and sample loop length (temperature $\left.\cong 23^{\circ} \mathrm{C}\right)$; b) temperature of reaction (loop $=120 \mathrm{~cm}$, stop-flow time $\left.=5 \mathrm{~min}\right) ; \mathrm{c}$ ) sulfite concentration in the reaction medium (arrow : SFA value after Kérouel and Aminot, 1997). In a and $b$ : sulfite concentration not optimized. Other conditions: ammonium in a and $c$, $10 \mu \mathrm{mol} \mathrm{I} \mathrm{I}^{-1}$, in $\mathrm{b}, 5 \mu \mathrm{mol} \mathrm{I}{ }^{-1}$; fluorometer attenuation, 100; recorder set, $10 \mathrm{mV}$ (automatic scale shift).

the effect of increasing sulfite concentration on peak height. The optimum concentration selected was close to that giving the highest response $\left(0.76 \mathrm{mmol}^{-1}\right.$ in reaction medium $)$. It is 
significantly different from that found in the SFA version $\left(0.055 \mathrm{mmol}^{-1}\right)$, but is closer to that used by Genfa and Dasgupta (1989) in their fresh water FIA method (1.1 mmol $\left.\mathrm{l}^{-1}\right)$. These results confirm that, for optimal performance, reagent concentrations may have to be adjusted when the manifold is modified.

\subsection{Performances of the method}

Although the method is about 100 times less sensitive than the SFA version, the signals obtained are very satisfactory (Fig. 3) since SFA signals were strongly attenuated (Kérouel and Aminot, 1997). The throughput is about nine samples per hour. Calibration curves were built up to $50 \mu \mathrm{mol} \mathrm{l}^{-1}$ in seawater (salinity of 35 on the seawater Practical Salinity Scale 1978, PSS78) and $100 \mu \mathrm{mol}^{-1}$ in $«$ estuarine water » (salinity $=5$ ). Linearity is observed up to $50 \mu \mathrm{mol} \mathrm{l}^{-1}$, while quadratic standardization should be applied if concentrations up to 100 $\mu \mathrm{mol} \mathrm{l}^{-1}$ are to be measured without dilution (Fig. 4).

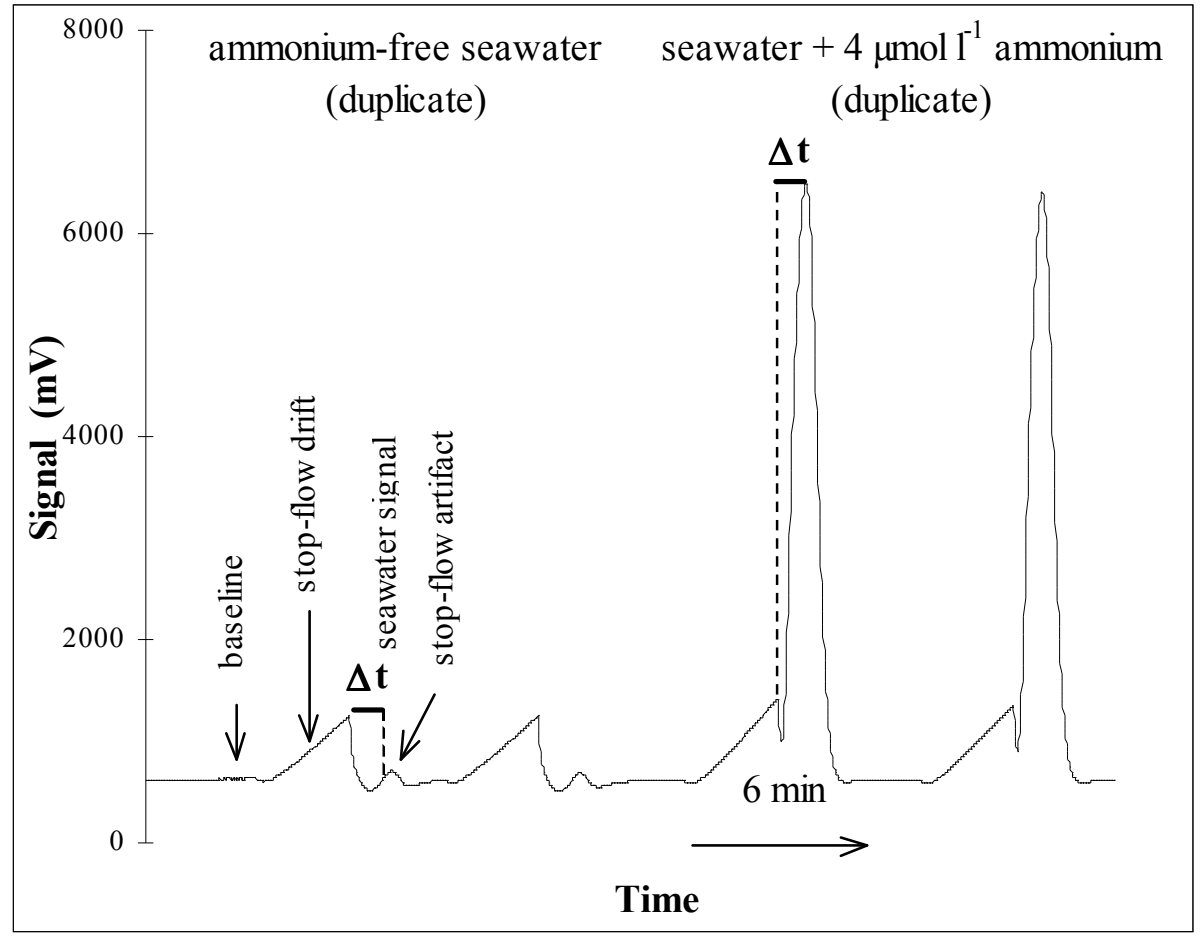

Figure 3. Example of peaks obtained for an ammonium-free seawater and for an ammonium standard $\left(4 \mu \mathrm{mol}^{-1}\right)$ in this seawater. Stop-flow artifacts do not prevent measuring low signals at the fixed time $\Delta t$ (determined from high signals) after flow re-starting.

Repeatability was checked on series of five successive measures of three standards: $0.5 \mu \mathrm{mol} \mathrm{l}^{-1}$ at a salinity of 35 and $4.0 \mu \mathrm{mol} \mathrm{l}^{-1}$ at salinities of 35 and 18 . The coefficients of variation were, respectively, 1.5, 0.4 and $0.9 \%$. From a duplicate analysis series of 10 natural samples in the range of 0.3-7 $\mu \mathrm{mol} 1^{-1}$ of ammonium (salinity : 23-35), the standard deviation was $0.03 \mu \mathrm{mol}^{-1}$ (gaps were within $\pm 0.02 \mu \mathrm{mol} \mathrm{l}^{-1}$ below $4 \mu \mathrm{mol} 1^{-1}$ and $\pm 1.5 \%$ above).

The limit of detection (LOD) was determined as being three times the standard deviation of a small concentration (Taylor, 1990). Using the repeatability test at the $0.5 \mu \mathrm{mol}^{-1}$ level,

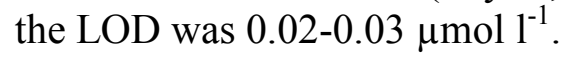



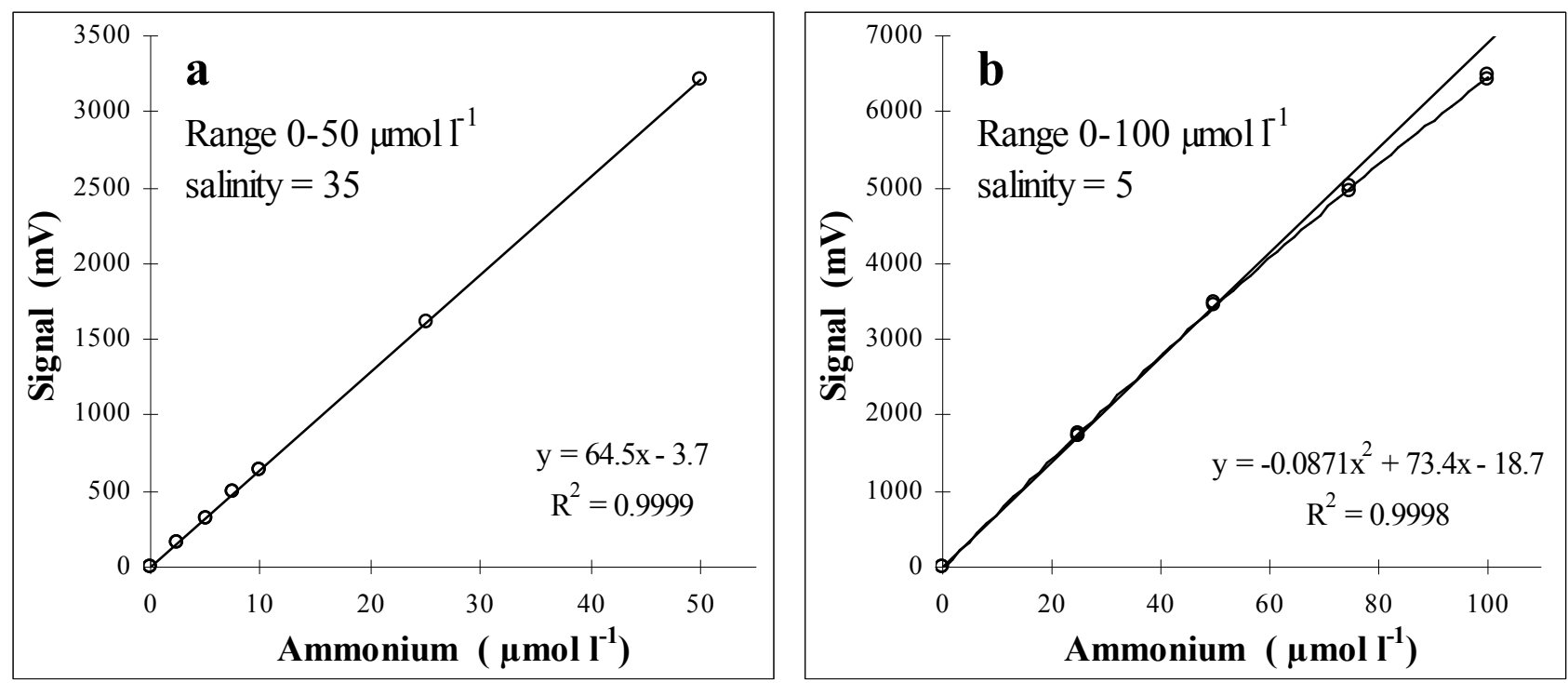

Figure 4. Typical ammonium calibration curves: a) linear adjustment up to $50 \mu \mathrm{mol}^{-1}$; b) quadratic adjustment up to $100 \mu \mathrm{mol} \mathrm{I}{ }^{-1}$.

Both aged OPA crystals and aged working reagent more or less amplify the stop-flow baseline artifact which appears with seawater. Care should be taken when measuring very low signals at a fixed time (determined by reference to a standard peak top) after the flow is restored (see Fig. 3). The "zero concentration" level may, therefore, differ from the baseline by up to $0.1 \mu \mathrm{mol}{ }^{-1}$, but calibrations using at least one low and one high standard will correct for that difference, if an optimum performance at low ammonium concentration is needed.

\subsection{Interferences}

The effect of important characteristics of natural waters on peak height was tested. These are the hydrogen carbonate concentration in fresh water, salinity (range 0-35), dissolved oxygen and sulfide. Additionally, the interference of mercury II, currently used as a preservative for samples and standards, was tested. For these tests, the net response of a standard at the level of $4 \mu \mathrm{mol} 1^{-1}$ of ammonium was measured as a function of the various water characteristics. Changes in reaction conditions compared with the SFA version also required the re-assessment of the response of primary amines (the main OPA reactive substances).

For hydrogen carbonate in the range of 0-370 $\mathrm{mg} \mathrm{l}^{-1}\left(0-6 \mathrm{mmol} \mathrm{l}^{-1}\right)$, no significant effect could be measured within the precision of the method (Fig. 5a). The buffering capacity of the reagent matched that of hydrogen carbonate and the peak height was not altered by the hydrogen carbonate concentrations found in most natural fresh waters.

The salt effect was measured as being the difference between the reference signal in sea water with salinity of 35 and the signal in less saline waters (obtained by mixing 

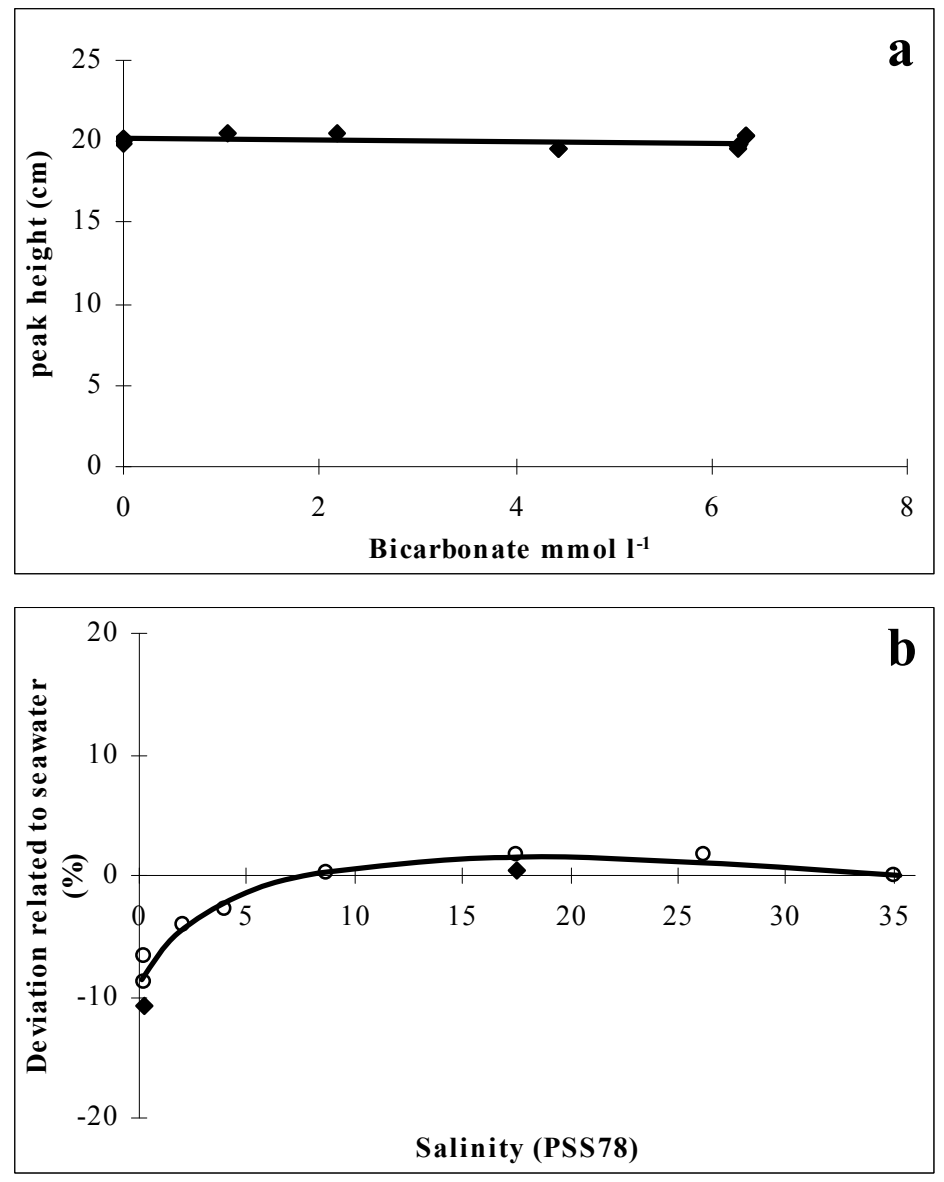

Figure 5. Effect of hydrogen carbonate concentration and salinity on the response of ammonium in the FIA-OPA method. a) Variation of peak height as a function of hydrogen carbonate concentration in fresh water. b) Deviation of a standard response $\left(4 \mu \mathrm{mol} \mathrm{l} \mathrm{I}^{-1}\right)$ as a function of salinity, in percent of response measured in seawater (salinity $=35$ ); mixtures of seawater with demineralized water $(O)$ and natural spring water $(\diamond)$.

demineralized water and seawater with salinity of 35). The effect measured then in FIA (Fig. 5b) is minor $(<+2 \%)$ in the salinity range $10-35$, and very similar to that found by Kérouel and Aminot (1997) using a SFA method. A difference is noted below a salinity of 10 , where the response decreases regularly down to about $-9 \%$ in fresh water. Three determinations in fresh water confirmed this drop within $\pm 2 \%$, a variability close to the normal performance. Overall, within a $\pm 2 \%$ uncertainty, results can be assumed to be independent of salinity over a salinity range of 5-35. The seawater was also mixed with natural spring water (composition in $\mathrm{mg}^{-1}$ : hydrogen carbonate 84 , chloride 37 , sulfate 20 , sodium 33, magnesium 10, calcium 8). Results compared well with those obtained in seawater diluted with demineralized water. The above results on the hydrogen carbonate effect indicate that this compound cannot be involved in the salt effect. The difference with SFA highlights how the reaction conditions may influence some performances of the method.

Dissolved oxygen is known to be a fluorescence quencher. Its concentration was increased up to $\sim 30 \mathrm{mg} \mathrm{l}^{-1}$ by strong bubbling $\left(300 \mathrm{ml} \mathrm{min}^{-1}\right)$ of high purity oxygen in $80 \mathrm{ml}$ of a standard, prepared in seawater, for $4 \mathrm{~min}$. The difference with the normal air saturated sample $\left(\mathrm{O}_{2}: \sim 8 \mathrm{mg} \mathrm{l}^{-1}\right)$ remained lower than $1 \%$, which was considered as not significant. A similar experiment, performed with the SFA method according to Kérouel and Aminot 
(1997), with oxygen concentrations of 3, 8 and $32 \mathrm{mg} \mathrm{l}^{-1}$ confirmed the absence of oxygen quenching within the precision of the ammonium determination.

Sulfide concentrations, tested up to $150 \mu \mathrm{mol} \mathrm{l}^{-1} \mathrm{~S}^{2-}$, produced a linear decrease of the signal by only $0.9 \%$ per $10 \mu \mathrm{mol} \mathrm{l}^{-1} \mathrm{~S}^{2-}$ (against $2.3 \%$ in the SFA version).

The depressive effect of mercury found in the SFA method was not detectable in the FIA method at a level of $20 \mathrm{mg}^{-1} \mathrm{Hg}$ II.

For primary amines (list of compounds in "Reagents" section) interference did not exceed $1 \%$, which is considered to be insignificant.

The reduction of interference, compared to the SFA version, is attributed to the higher sulfite concentration in the reagent, and this change might be applied to other OPAammonium methods.

\subsection{Effect of sample temperature}

Because of the reaction's great sensitivity to temperature changes at the selected temperature, it was important to check the effect of the sample temperature on the response for potential in situ applications. This was performed using ammonium standards $\left(8 \mu \mathrm{mol}^{-1}\right)$ refrigerated at $6{ }^{\circ} \mathrm{C}$ and heated to $33{ }^{\circ} \mathrm{C}$. The incidence on the peak height was not detectable. Although the temperature of the aliquot passed through the sample injection loop may differ slightly from the sample temperature, the experiment shows that the method withstands great variations of the sample temperature with unchanged response.

\subsection{Effect of sample particulate matter}

The effect of suspended matter in the water was tested with non-living suspended matter (sediments) and with pure phytoplankton cultures. Particle size was measured using a CILAS 850B laser granulometer.

The sediment test included two experiments. First, we added a pyrolyzed muddy estuarine sediment (particle size range : 1-250 $\mu \mathrm{m}$; median: $45 \mu \mathrm{m}$ ) to ammonium standards prepared in seawater. Pyrolyzing ensured that sediment was free of ammonium and organic matter, thus eliminating any unexpected interference. The absence of ammonium was checked in ammonium-free seawater (AFSW) mixed with $2 \mathrm{~g} \mathrm{l}^{-1}$ of the sediment, then centrifuged and analyzed. A second experiment was undertaken likewise with a fresh estuarine fine grain mud $(<50 \mu \mathrm{m})$, in order to simulate natural conditions up to $600 \mathrm{mg}^{-1}$ of suspended matter. The mud was suspended at a concentration of $120 \mathrm{~g} \mathrm{l}^{-1}$ in demineralized water and added to AFSW. As in the first experiment, samples had to be thoroughly stirred to avoid particle settling during analysis, and a slight ammonium contamination from air occurred. This effect was estimated $\left(\sim 0.15 \mu \mathrm{mol}^{-1}\right)$ by stirring AFSW in the same way as the turbid samples, and then corrected. The second sediment did not require stirring, but released a small amount of ammonium in the test samples. A correction was determined from AFSW spiked with the sediment suspension. The mean ammonium concentration measured in turbid water and attributable to ammonium present on the sediment itself did not exceed around $0.1 \mu \mathrm{mol} \mathrm{l}^{-1}$ for $1 \mathrm{~g} \mathrm{l}^{-1}$ suspended matter.

Table 1 summarizes the results of the relative effect of the presence of suspended sediments in the sample for determining the ammonium concentrations. Surprisingly, opposite effects were observed with the two sediments : slightly negative for the pyrolysed sediment 
and slightly positive for the natural sediment. Pyrolyzing may have activated adsorption sites which then protected fixed ammonium from reaction in the manifold. However, the main result is that, whatever the sediment, no major effect from turbidity could be detected up to $\sim 1 \mathrm{~g} \mathrm{l}^{-1}$ of suspended matter ( -5 to $+1 \%$ of the ammonium concentration).

\section{Table 1. Effect of the presence of suspended particulate matter on the response of a standard solution $\left(4 \mu \mathrm{mol} \mathrm{I}^{-1}\right)$ of ammonium by the FIA-OPA method.}

\begin{tabular}{|c|c|c|}
\hline \multicolumn{2}{|c|}{ Suspended particulate material } & \multirow{2}{*}{$\begin{array}{c}\text { Signal alteration } \\
\%\end{array}$} \\
\hline Type & $\begin{array}{l}\text { Concentration } \\
\text { mg }^{-1} \text { or cells } \mathbf{l}^{-1}\end{array}$ & \\
\hline \multirow[t]{2}{*}{ Pyrolyzed sediment } & 220 & -3 \\
\hline & 950 & -5 \\
\hline \multirow[t]{3}{*}{ Fresh sediment } & 120 & +0.7 \\
\hline & 300 & +0.5 \\
\hline & 600 & +1 \\
\hline Diatoms (Chaetoceros gracile) & $5.10^{6}$ & 0 \\
\hline Diatoms (Thalassosira weissflogii) & $4.10^{6}$ & -2 \\
\hline
\end{tabular}

Potential interference from phytoplankton was tested with two types of ammonium-free diatom cultures : Chaetoceros gracile and Thalassosira weissflogii. Dilutions were made to obtain about $5.10^{6}$ and $4.10^{6}$ cells per liter, i.e., roughly 50-60 $\mu \mathrm{g} \mathrm{l^{-1 }}$ chlorophyll $a$, in the test samples. In ammonium-free seawater, no response from the algae was detected (note that ammonium from the culture media was undetectable at the dilution rate used). The effect of phytoplankton on ammonium standards, 0 and $-2 \%$ on average (Table 1), is not significant since the assimilation rate of ammonium by the algae during analysis of the replicates is liable to explain the negative value.

\subsection{Background fluorescence}

Background fluorescence (BF) from naturally occurring organic compounds may not be negligible in some fresh waters, as mentioned by Holmes et al. (1999). In addition, the present application of OPA determination of ammonium operates far from the signal's maximum, contrary to the SFA version from Kérouel and Aminot (1997). Therefore, it should be checked whether or not correction of BF has to be applied, depending on the allowed precision as a function of the expected ammonium level.

A study of BF spectral data was undertaken on six samples of fresh waters from small rivers and ponds, using a Jasco FP 1520 spectrofluorometer. Fluorescence spectra of the samples were obtained by replacing the normal reagent with an OPA-free reagent. The excitation wavelength was the same as for measuring ammonium, $370 \mathrm{~nm}$. The spectra confirmed the findings of Holmes et al. (1999) that the BF and the fluorescence of the ammonium-OPA compound overlap, and that it is not possible to significantly reduce BF interference by selecting a particular emission wavelength. Ammonium equivalents for these background fluorescence signals, measured with the LDC detector in the same way as for the samples, but with an OPA-free reagent, were in the range of $0.10-0.14 \mu \mathrm{mol}^{-1}$. Seawater's background fluorescence is not detectable in the given analytical conditions. 


\subsection{Validation of the method}

A comparison of results obtained with this method and with the SFA method from Kérouel and Aminot (1997) was made with samples from the Bay of Seine (France) whose salinities were between 23.1 and 34.7. Figure 6 shows that the data compare well (slope: 1.01; intercept: $\left.0.05 \mu \mathrm{mol} \mathrm{l}^{-1}\right)$. The confidence intervals (95\% confidence level) show that the slope is not significantly different from $1( \pm 0.02)$ and the intercept not significantly different from zero $\left( \pm 0.07 \mu \mathrm{mol} \mathrm{l}^{-1}\right)$.

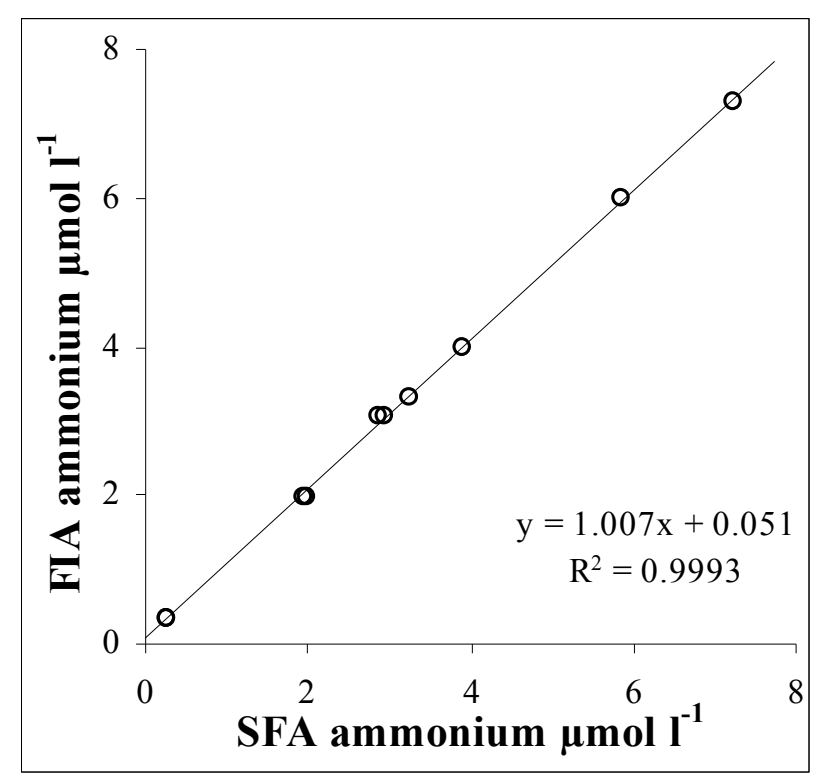

Figure 6. Comparison of ammonium concentration values obtained with the present FIA method and the SFA version from Kérouel and Aminot (1997). Test conducted using natural samples from the Bay of Seine (English Channel, French coast).

\section{DISCUSSION AND CONCLUSION}

This work indicates the capabilities of a FIA-fluorescence method for determination of ammonium in fresh or saline natural waters. In the context of potential application to in situ, limited-energy, systems, a low reaction temperature was an initial criterion. Therefore, reaction conditions differ greatly from those applied in segmented flow analysis (Kérouel and Aminot, 1997) and it was necessary to re-optimize reaction parameters to maintain acceptable performances. Despite the slow rate of the OPA-sulfite-ammonium reaction (several hours at ambient temperature), the sensitivity of fluorescence enables good signals to be obtained with FIA used in the stop-flow mode. Comparison of signals without and with the flow stopped for 3 min shows that sensitivity is multiplied by more than 30 when the total reaction time is increased from about $1.5 \mathrm{~min}$ (non stop-flow mode) to $4.5 \mathrm{~min}$ (stop-flow mode). Under the defined conditions, a time of 6 min per sample enables both the baseline and the sample signal to be measured. Although apparently low, this throughput is satisfactory for data recording from analyzers placed aboard automatic buoys, for example, a type of equipment which is currently developing in environmental studies and monitoring (Woerther and Grouhel, 1997; Wright et al., 1997). In our development, we checked the method with heavy constraints on 
energy: low temperature combined with rather short reaction time to obtain acceptable performance. Nevertheless, if more energy is available, the method's flexibility allows two options to be considered. Increasing the time of stopped flow from 3 to $5 \mathrm{~min}$, for instance, increases the response by a factor of $\sim 3$, hence likewise improving the signal-to-noise ratio, since artifacts remain almost constant (overall precision is increased). In the laboratory, or if high throughputs are expected (for in situ profiles for instance) working at a higher temperature, without stopping the flow, seems a more satisfactory option. Indeed, tests at $50{ }^{\circ} \mathrm{C}$ showed that working in the non-stop flow mode produces performances similar to those given above $\left(30^{\circ} \mathrm{C}\right.$, stop-flow), but at a frequency of about $40 \mathrm{~h}^{-1}$.

The stability of the method's response, despite changes of water parameters such as hydrogen carbonate, dissolved oxygen, and, to a lesser extent, salinity, is a major advantage for use in changing environments where other techniques would require much complex chemistry or would even fail. The very low alteration due to high water turbidity and phytoplankton concentration is interesting since samples do not have to be filtered before analysis, saving power for in situ systems. The reduction of sulfide interference is essential for methods used for in situ measurements in estuarine, deep-sea hydrothermal vent or anoxic basin environments, for instance, where these species may be present. Since this interference is low and linear as a function of sulfide concentration, the data can be corrected if the sulfide concentration is known.

This application of OPA ammonium determination may be compared with the FIA ammonium method proposed by Willason and Johnson (1986) to be adapted to a submersible analyzer. Their method, based on membrane separation of $\mathrm{NH}_{3}$, then colorimetric detection of $\mathrm{pH}$ change in a buffer, is of comparable sensitivity but more rapid than this method. However, some problems due to the membrane are pointed out by the authors (clogging, calibration drift), in addition to a very high salt effect mentioned by Jones (1991) and Gibb et al (1995). Willason and Johnson's method (1986) is suitable for short term measurements at constant salinity and is probably unaffected by turbidity owing to membrane separation of ammonia, but it does not seem satisfactory for monitoring coastal and estuarine waters where salinity is variable.

This ammonium FIA-fluorescence method was tested under conditions representing quasi natural, or even extreme situations that can be encountered by an in situ analyzer operating with this type of method. Since the method is little affected by changes in major water characteristics, within the concentrations encountered in most areas, a field study could not provide additional data on its applicability. Obviously, overall performance for in situ determination will probably be slightly less than under optimum laboratory conditions with non-turbid samples and correction of salt effect and background fluorescence. However, no previous method for the determination of ammonium has been able to work acceptably in such a wide range of constraints and environmental conditions. In this method, no filtration device needs to be set up on in situ systems since suspended particulate matter has a negligible effect on the measures. We are currently developing a submersible device for ammonium determination. It is derived from an in situ nitrate analyzer (Daniel et al., 1995a), but the colorimeter will be replaced by a low-power fluorometric detector.

\section{ACKNOWLEDGEMENTS}

We thank our colleagues E. Erard and M. P. Crassous for providing phytoplankton cultures and data on cell counts, Philippe Bassoulet for particle size determination and JeanClaude Caprais and Pierre-Marie Sarradin for preparing reliable sulfide standards. 


\section{REFERENCES}

Aminot A., Kirkwood D.S. and Kérouel R. (1997) Determination of ammonia in seawater by the indophenol blue method: evaluation of the ICES NUTS I/C 5 questionnaire. Mar. Chem. 56, 59-75.

Daniel A., Birot D, Blain S., Tréguer P., Leïldé B. and Menut E. (1995a) A submersible flowinjection analyser for the in-situ determination of nitrate and nitrite in coastal waters. Mar. Chem. 51, 67-77.

Daniel A., Birot D, Lehaitre M. and Poncin J. (1995b) Characterization and reduction of interferences in flow-injection analysis for the in-situ determination of nitrate and nitrite in sea water. Anal. Chim. Acta 308, 413-424.

Genfa Z. and Dasgupta P.K. (1989) Fluorometric measurement of aqueous ammonium ion in a flow injection system. Anal. Chem. 61, 408-412.

Gibb S.W., Mantoura R.F.C. and Liss P.S. (1995) Analysis of ammonia and methylamines in natural waters by flow injection gas diffusion coupled to ion chromatography. Anal. Chim. Acta 316, 291-304.

Holmes R. M., Aminot A., Kérouel R., Hooker B. A. and Peterson B. J. (1999) Fluorometric measurement of ammonium in marine and freshwaters. Can. J. Fish. Aquat. Sci.s 56, 18011808.

Johnson K. S., Beehler C. L. and Sakamoto-Arnold C. M. (1986) A submersible flow analysis system. Anal. Chim. Acta 179, 245-257.

Johnson K. S., Sakamoto-Arnold C. M. and Beehler C. L. (1989) Continuous determination of nitrate concentrations in-situ. Deep-Sea Res. 36, 1407-1413.

Jones R.D. (1991) An improved fluorescence method for the determination of nanomolar concentrations of ammonium in natural waters. Limnol. Oceanogr. 36 (4), 814-819.

Kérouel R. and Aminot A. (1997) Fluorometric determination of ammonia in sea and estuarine waters by direct segmented flow analysis. Mar. Chem. 57, 265-275.

Taylor J.K. (1990) Quality assurance of chemical measurements. Lewis Publishers, Inc., USA, $328 \mathrm{pp}$.

Thomsen J., Johnson K. S. and Petty R L. (1983) Determination of reactive silicate in seawater by flow-injection analysis. Analytical Chemistry 55, 2378-2382.

Vuillemin R., Thouron D., Gallou G., Parès L., Brient B., Dubreule A. and Garçon V. (1999) ANAIS : Autonomous Nutrient Analyzer In-Situ. Sea Technol. 40 (4), 75-78.

Willason S. W. and Johnson K. S. (1986) A rapid, highly sensitive technique for the determination of ammonia in seawater. Mar. Biol. 91, 285-290.

Woerther P. and Grouhel A. (1997) Automated measurement network for the coastal environment. Hydro International 1 (5), 37-39.

Wright P.N., Hydes D.J., Lauria M.-L., Sharples J. and Purdie D. (1997). Data buoy measurements of phytoplankton dynamics in Southampton Water, UK, a temperate latitude estuary with high nutrient inputs. Deutshes Hydrographisches Zeitschrift 49, 201-210. 